\title{
Evaluation of a teaching hospital necropsy service
}

\author{
E. FIONA FOWLER, A. G. NICOL, AND I. N. REID \\ From the Department of Pathology, University Medical Buildings, Foresterhill, Aberdeen AB9 2ZD, Scotland
}

SUMMARY The information returned to the hospital clinician after a necropsy was investigated in a series of 1000 patients. It was found that specific clinical queries were answered in $83 \%$ of cases, that the necropsy corrected the major clinical diagnosis in $36 \%$ of cases, and that $29 \%$ of cases were used for undergraduate or postgraduate teaching. The results demonstrate the continuing value of the necropsy as an investigative and educative procedure.

The routine hospital necropsy is directly or indirectly useful to a number of individuals and institutions (Figure). The hospital clinician plays an important part in passing on information and also has the initial task of requesting permission for necropsy from bereaved relatives.

There have been conflicting reports about the potential value of the routine necropsy (Wilson, 1966; Prutting, 1967; Burrows, 1975) and, unless our present and future clinical colleagues are convinced of its worth, necropsy rates, already low, will fall further (Hasson and Gross, 1974; Waldron and Vickerstaff, 1975). We have therefore investigated the value of the necropsy as an information source to clinician and medical student.

\section{Methods}

POSTMORTEM EXAMINATION REQUEST FORM $A$ request form introduced into the Aberdeen general hospitals in late 1972 is now completed routinely after permission for necropsy has been received (Table 1). The clinician gives a succinct summary of the case but can also emphasise those

Received for publication 1 November 1976
Table 1 Postmortem examination request form (abbreviated)

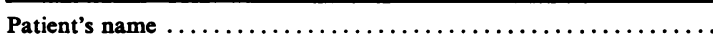

Address

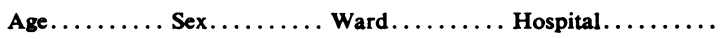

Consultant ........................ Time of death.....

Summary of clinical findings.

Clinical diagnosis

Any conditions or treatments likely to cause hazard at necropsy ?....

Which details do you particularly hope will be illustrated or clarified by the postmortem examination?

aspects in which he has particular interest and which require elucidation. The form commits the clinician to a clear and final diagnosis at the time of the patient's death. This may, of course, differ from that made at an earlier stage in the illness.

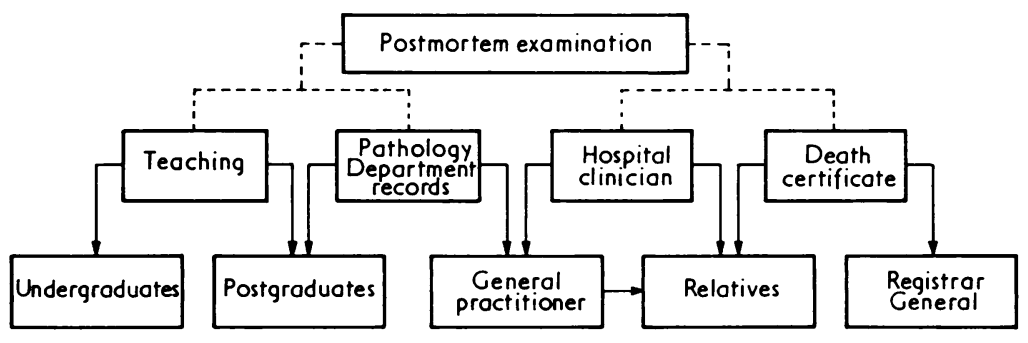

Figure Recipients of information gained at necropsy. 


\section{NECROPSY RECORDS}

All necropsies were performed and reported by members of staff of the Department of Pathology, University of Aberdeen. Details of cases used for teaching were obtained from departmental teaching records.

From 1038 consecutive non-fiscal necropsies performed on patients who had died in the Royal Infirmary, Woodend General Hospital and City Hospital, Aberdeen, we rejected 38 cases for which the request form was absent or incomplete; these belonged to no apparent subgroup or population. The hospitals concerned admit acute medical and surgical, geriatric, and infectious diseases patients. No psychiatric or paediatric cases were included in the series. The 1000 acceptable cases represented $37 \%$ of total hospital deaths between November 1972 and June 1974, including 521 males, mean age 66 (range 14-98) years, and 479 females, mean age 71 (range 13-103) years.

\section{ANALYSIS}

We employed request forms, necropsy reports, and teaching records to investigate information return under the following headings:

\section{Clinical requests}

For each case, answers given by the pathologist to specific clinical questions were assessed as wholly satisfactory when all questions had been fully answered, and firm anatomical localisation of specific pathology confirmed (where appropriate) by histological examination. They were judged as unsatisfactory when the clinicians' queries remained unanswered or the answers were found to be unconvincing by the reviewing panel (EFF, AGN, INR, in consultation).

\section{Clinical diagnosis}

We assessed the accuracy of clinical diagnosis in respect of both major pathological processes and secondary or minor pathology. For the former, the request form diagnosis was judged correct if the lesion specified was shown at necropsy to have been the primary cause of death and/or the condition predominantly responsible for the patient's final illness. We recorded as secondary pathology all disease processes identified at necropsy which were important complications of the primary cause of death or, though unrelated to the cause of death, would themselves have been likely to cause morbidity. The clinical diagnosis of secondary pathology was judged correct if the existence of these conditions was stated or implied on the request form.

\section{Teaching}

We determined the frequency with which material or information obtained at necropsy had been used for $\overline{\vec{s}}$ undergraduate or postgraduate teaching.

\section{Results}

\section{CLINICAL REQUESTS}

Clinical questions per case varied in number (mean number of questions $=2$, range $0-7$ ) and also in content (Table 2). The most frequent requests were for the identification of pathological processes to account for prominent signs and symptoms, the confirmation of clinical diagnosis, or the determination of the mechanism of death.

Many of the requests in the group headed 'extent

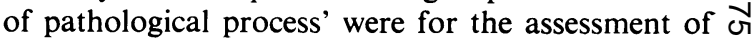
severity and situation of myocardial damage in $\mathrm{O}$ ischaemic heart disease. The extent or source of malignant disease was often requested.

Table 2 Analysis of clinical requests

\begin{tabular}{lr}
\hline Request & $N o$. \\
\hline Identify pathology to account for prominent symptoms or signs & 629 \\
Confirm clinical diagnosis & 462 \\
Establish cause of death & 327 \\
Determine extent of pathological process (other than tumour) & 156 \\
Determine extent of tumour spread & 121 \\
Determine primary site of tumour & 82 \\
Establish source of bleeding & 46 \\
Establish state of operation wound/site & 32 \\
Miscellaneous & 204 \\
Total requests $\left(977\right.$ cases $^{1}$ ) & 2059 \\
& \\
\hline No questions
\end{tabular}

${ }^{1}$ No questions were asked in 23 cases.

ASSESSMENT OF ANSWERS

Necropsy report answers to clinical requests were judged as satisfactory for $83 \%$ of the patients studied, partially satisfactory in $12 \%$, and unsatisfactory in $2 \%$ (Table 3 ).

Table 3 Assessment of answers to clinicians' queries

\begin{tabular}{lcc}
\hline Answer & No. cases & $\%$ cases \\
\hline Satisfactory & 833 & $83 \cdot 3$ \\
Partially satisfactory & 122 & $12 \cdot 2$ \\
Unsatisfactory & 22 & $2 \cdot 2$ \\
No questions asked & 23 & $2 \cdot 3$ \\
$\quad$ Total & 1000 & 100 \\
\hline
\end{tabular}

Why were requests unanswered?

We further investigated the 144 cases in which necropsy had not provided the full solution to the clinical problems. In 73 cases we considered the necropsy had been poorly performed or reported. Although some of the specific requests on the form had been answered, others had been neglected with no detailed account of the structure or organ which had aroused clinical interest.

In a further 71 cases, the solution of a clinical 
problem proved impossible despite an adequately performed and reported necropsy. Table 4 categorises these failures. In the whole series, 54 requests were made for biochemical or haematological information, and in 20 cases $(37 \%)$ this was not supplied. There was a failure rate of $26 \%$ (12 cases from a total of 46) in identifying the source of bleeding. The pathologist's failure to identify the primary site of a malignant tumour in eight cases represented $10 \%$ of the total requests for this information.

Table 4 Examples of failure to answer specific clinical questions after adequately performed necropsy

\begin{tabular}{|c|c|}
\hline Request & No. of failures \\
\hline Biochemical/haematological & 20 \\
\hline \multicolumn{2}{|l|}{ Identify source of bleeding: } \\
\hline gastrointestinal & 5) \\
\hline intracranial & 4 \\
\hline genitourinary & \\
\hline ? respiratory ? gastrointestinal & 1) \\
\hline Identify primary site of malignant tumour & 8 \\
\hline Identify mechanism of death & 7 \\
\hline \multicolumn{2}{|l|}{ Questions relating to: } \\
\hline Gastrointestinal system * & 7 \\
\hline Central nervous system* & 3 \\
\hline Genitourinary system ${ }^{*}$ & 2 \\
\hline Cardiovascular system & 2 \\
\hline Respiratory system & 1 \\
\hline Endocrine system & 1 \\
\hline Musculoskeletal system & 1 \\
\hline Others & 7 \\
\hline Total & 71 \\
\hline
\end{tabular}

*Excluding haemorrhage

\section{Accuracy of clinical diagnosis}

The clinical diagnosis of the major lesion or lesions which had caused death was totally correct with accurate prediction of findings in $64 \%$ of cases and inaccurate or misleading in $36 \%$. The clinical prediction of minor or additional pathology was less accurate, correct prediction being made in $35 \%$ of cases and the minor pathology remaining undiagnosed or wrongly diagnosed in $65 \%$. Details of the disease processes involved, and comparisons of clinical, pathological, and death certificate diagnosis will be published elsewhere.

\section{USE OF NECROPSY FOR TEACHING}

Of the 1000 cases studied, material from 288 necropsies was employed for teaching purposes. Some cases, however, were used more than once for presentation to different groups. Organs and tissue samples from 263 cases were demonstrated to clinical undergraduate students at postmortem teaching sessions either conventionally in the postmortem theatre or by closed-circuit television (Nicol et al., 1976). Seventeen cases were used as a source for clinicopathological conferences given to fifth-year undergraduates during their medicine teaching block, including three cases previously demonstrated to fourth-year students. A further 11 cases not previously shown were included in the 32 cases discussed at postgraduate clinicopathological conferences.

\section{Discussion}

There have been numerous investigations comparing antemortem and postmortem diagnosis (Munck, 1952; Holler and De Morgan, 1970; Britton, 1974a, b) or determining the frequency with which a specific lesion or process had been unsuspected during life but was identified at necropsy (Hällén and Nordén, 1964; Cooper et al., 1966). However, in our survey we have assessed the response to a wide variety of clinical requests and we are unaware of any similar study involving a comparable hospital population.

In a high proportion of cases the necropsy gave full and definite answers to those questions which had puzzled or intrigued the clinician and had been set down before the necropsy was performed. We see less scientific value in any assessment which depends upon circularising the clinician after the event, asking whether or not he is satisfied; we consider this latter method too prone to subjective variation.

The request forms were usually completed by the house officer or registrar rather than by the consultant in charge of the patient. We have assumed that the junior staff had been 'briefed' by the consultant on those aspects of the case which were of particular interest. However, if this assumption was unfounded then the necropsy elucidated points which interested the junior staff themselves. Now and in the future it is they who will seek permission for necropsy from relatives or will promote the value of the necropsy. We therefore see no fundamental objection if in some cases we answer questions for junior rather than for senior medical staff.

In many of the inadequately answered cases a conscientious but unsuccessful investigation had been made by the pathologist. It should be of value to clinician and pathologist alike to know in advance the type of problem that is likely to prove difficult to solve, and Table 4 may give some guidance since it exemplifies the type of specific clinical question that is difficult to answer at necropsy.

There were frequent difficulties in identifying the precise sources of bleeding. This can be an awkward problem when blood flow has ceased, and it may be that injection or perfusion techniques should be more routinely applied at necropsy.

Inevitably, questions on metabolic or haematological matters were poorly answered, since they asked for information which is obscured after death by changes in tissue and body fluids.

In 73 cases the postmortem report conveyed the 
impression that little attention had been paid to the clinician's request. The pathologist had performed the necropsy 'to his own satisfaction' but had not referred to the specific points mentioned by the clinician-precisely the situation which it was hoped the request form would prevent. In some reports the lack of comment on a structure or system could perhaps be construed as an indication that it was entirely normal, but this is an unacceptable response to a specific query. This finding argues strongly for the importance of continual personal and departmental audit of necropsy reports.

Major pathological processes unspecified in the clinical diagnosis were found at $36 \%$ of necropsies, providing direct informational return to the clinician and perhaps suggesting possible changes in treatment or management when similar clinical features are next encountered. The frequent correction of the major diagnosis, and the numerous conditions first uncovered post mortem, emphasise the continuing value of the necropsy as an investigative procedure.

We have sought to define the 'return' which the necropsy gives to the clinician and have shown the frequency with which specific clinical queries are answered, antemortem diagnoses are amended, and material is employed for teaching purposes. The clinician, pondering the need to arrange a necropsy, may ask himself, and indeed may be asked by the patient's next-of-kin, whether the exercise is worthwhile. We hope he will regard our findings as strongly affirmative and that they may do something to arrest the necropsy"s decline.

We thank clinical and departmental colleagues for their cooperation and Professor A. L. Stalker for advice.

\section{References}

Britton, M. (1974a). Diagnostic errors discovered at autopsy. Acta. med. scand., 196, 203-210.

Britton, M. (1974b). Clinical diagnostics; experience from 383 autopsied cases. Acta. med. scand., 196, 211-219.

Burrows, S. (1975). The postmortem examination: \& scientific necessity or folly? J. Amer. med. Ass., 233, 441-443.

Cooper, E. S., Cooper, J. W., and Schnabel, T. G., Jr. (1966). Pitfalls in the diagnosis of bacterial endocarditis. A review of 159 patients with emphasis on 96 with autopsy. Arch. intern. Med., 118, 55-61.

Hällén, J. and Nordén, J. (1964). Liver cirrhosis unsuspected during life. A series of 79 cases. J. chron. Dis., 17, 951-958.

Hasson, J. and Gross, H. (1974). The autopsy and quality assessment of medical care. Amer. J. Med., 56, 137-140.

Holler, J. W. and De Morgan, N. P. (1970). A retrospective study of 200 postmortem examinations. $J$. med. Educ., 45, 168-170.

Munck, W. (1952). Autopsy finding and clinical diagnosis A comparative study of 1000 cases. Acta med. scand. Supplement, 266, 775-781.

Nicol, A. G., Grimley, A., and Morton, R. (1976). Post-mortem teaching using colour television. Med. biol. Ill., 26, 31-34.

Prutting. J. (1967). Lack of correlation between antemortem and postmortem diagnoses. N.Y.S. J. Med., 67, 2081-2084.

Waldron. H. A. and Vickerstaff, L. (1975). Necropsy rates in the United Birmingham hospitals. Brit. med. J., 2, 326-328.

Wilson. R. R. (1966). In defense of the autopsy. J. Amer. med. Ass.. 196, 1011-1012. 